\title{
CAN THAT BE TRUE OR IS IT JUST FAKE NEWS?
}

\section{New perspectives on the negativity bias in judgments of truth}

\author{
Mariela E. Jaffé and Rainer Greifeneder
}

\section{Introduction}

Which of the two statements do you believe is true: (1) $80 \%$ of marriages last ten years or longer or (2) $20 \%$ of marriages are divorced within the first ten years? Which one of them is more likely to be fake news? As a reader, you may come to the conclusion that the authors must have made a mistake - both statements are content-wise identical and therefore can only both be true or false. Indeed, logically speaking, the statements are identical. Nevertheless, when individuals are asked to judge the statements' truthfulness, the estimates differ depending on whether they read the positively (1) or negatively (2) framed version of the same fact. In particular, research has shown that the negatively framed statement (2) that focuses on the divorce rate is more likely to be judged as true compared to the positively framed version (1) that focuses on marriage duration (Hilbig, 2009). This bias has been coined negativity bias in truth judgments (Hilbig, 2009, 2012a, 2012b) and describes the tendency that negatively framed compared to positively framed but content-wise identical statements are more likely to be judged as true. In this chapter, we deep dive into the bias's psychological mechanics and suggest that there is more to understand about this bias than previously assumed. We summarize current research on the bias and further analyze how and when the negativity bias does (not) influence and eventually bias individuals' judgments of truth. This summary sheds light on the malleability of truth judgments and provides information on how the communication format can make information sound very compelling while its content still is false or fake.

\section{Truth or post-truth? A currently ongoing discussion}

Telling the truth is crucial to our daily interactions. If we ask somebody a question, we generally assume that the person will reply with information that he or 
she believes is true. This belief is a pragmatic necessity for the successful functioning of human communication: when engaging in interpersonal interactions individuals are expected and expect from their counterparts that they follow the so-called cooperative principle (Grice, 1975). This cooperative principle asks individuals to "make your conversational contribution such as it is required, at the stage at which it occurs, by the accepted purpose or direction of the talk exchange in which you are engaged" (Grice, 1975, p. 45). This cooperative principle is the summary of sub-principles, of which one is the maxim of quality. The maxim of quality states that one should not say what one believes to be false and one should also not say something for which one lacks adequate evidence. In sum, one should speak the truth and therefore the counterpart can expect to be told the truth.

Although truthfulness appears to be fundamental for human interactions, post-truth has been elected as word of the year 2016, "relating or denoting circumstances in which objective facts are less influential in shaping public opinion than appeals to emotion and personal beliefs" (Oxford Dictionary, 2016). The Oxford Dictionary argued that the frequency of usage spiked in the context of the 2016 EU referendum in the United Kingdom and the 2016 presidential election in the United States and has therefore been associated with the particular noun of post-truth politics. It reflects the general assumption that we are entering a time "in which the specified concept [of truth] has become unimportant or irrelevant", especially in the context of politics (Oxford Dictionary, 2016). The Independent author Matthew Norman agrees and notes "the truth has become so devalued that what was once the gold standard of political debate is now a worthless currency" (Norman, 2016) - and instead so called alternative facts are presented by candidates and politicians alike.

In a world of post-truth politics, alternative facts, and uncertainty, telling what is true or false has arguably become more difficult than before. The Guardian suggested that countering fake news with "fact checkers" as weapons of choice is crucial, and that journalism has to get better at spreading facts to show people what is actually happening (Jackson, 2017). However, to be able to convince individuals of the truthfulness of these facts and successfully warn them about fake news, one first needs to better understand how individuals decide whether they believe something is true or false. In this chapter, we focus on one particular aspect of this question, the negativity bias in judgments of truth.

\section{How do individuals judge truth?}

Grice (1975) assumed that individuals start from the premise that others are telling the truth (see also Marsh \& Stanley, this volume). Consistent with this basic tenet, individuals overestimate others' truthfulness, which is known as the truth bias (Burgoon, Blair, \& Strom, 2008; Reinhard, Greifeneder, \& Scharmach, 2013) and has been amply documented in a variety of contexts (e.g., Anolli, Balconi, \& Ciceri, 2003; Buller, Burgoon, White, \& Ebescu, 1994; Vrij \& Mann, 2001). 
If individuals, however, are not willing to start from the basic premise of truthfulness, they may resort to strategies to decide whether some piece of information is true or false. Dunwoody (2009), for example, summarized that the principles of coherence and correspondence (C\&C; Hammond, 1996, 2007) can be used as criteria to assess the truth-value of a statement, belief, or judgment. The correspondence theory of truth argues that a belief can be said to be true if it corresponds with the facts (Dunwoody, 2009, p. 117). As an example, to test correspondence, the accuracy of a weather forecast may be checked by comparing it to reality (Hammond, 1996, p. 95). For instance, if rain was predicted and it rained, the prediction was true, if not, it was false. However, this rather philosophical approach to truth was criticized by pragmatists and idealists in the nineteenth century (Dunwoody, 2009), as the notion of a fact was objected. This critic strengthened an alternative approach, the coherence theory of truth, in which truth is assessed via consistency of beliefs (Hammond, 1996). To test coherence or also rationality, one could check whether the arguments that lead to a certain conclusion meet the test of logical or mathematical consistency (Hammond, 1996, p. 95). Although coherence alone does not guarantees truth (Dunwoody, 2009), both C\&C theories of truth are informative about how individuals might come to a judgment regarding the truthfulness of a statement - they test whether the statement corresponds with facts that they know and/or if it is coherent to their beliefs.

The C\&C approach can be translated to distinct processes with which individuals judge a statement's truth. Reder (1982), for example, argues that individuals can verify a statement by either directly finding a close match to the query in memory (which may be perceived as being parallel to the correspondence principle), or by judging the plausibility of the statement (which may be perceived as being in parallel to the coherence principle). Reder (1982) furthermore argues that in everyday life it is unlikely that all facts or even the majority of facts on which people are queried are directly stored in memory, which render plausibility judgments the more frequent case.

But how do individuals derive and judge the plausibility of a message or piece of information? Especially when statements are ambiguous and when individuals do not have a lot of knowledge or strong beliefs (Dechêne, Stahl, Hansen, \& Wanke, 2010)? At least three sources of information may be relied upon to gauge plausibility: cues about the statement's source (e.g., the source's level of expertise on the subject matter), attributes of the context in which it is presented (e.g., at a scientific conference), and attributes of the statement itself to judge its veracity (see Dechêne et al., 2010).

Especially the attributes of the statements itself could impact the statements' plausibility directly and, by making them seem logically sound, also increase the associated coherence of the information. Attributes of the statement itself could include repetition (see, e.g., Stanley, Yang, \& Marsh, 2019) but also recognition, familiarity, processing experiences or fluency (e.g., Reber \& Schwarz, 1999; for a review, see Reber \& Greifeneder, 2017), and mental references (Unkelbach \& Koch, 2019; Unkelbach \& Rom, 2017). 
In this chapter, we focus on one attribute of the statement itself, namely the statement's conceptual frame, as detailed next. Consistent with Hilbig (2009) we here define conceptual frame as denoting something positive or negative. In research on the negativity bias, a statement's positive or negative frame is manipulated by describing something positive or negative (Hilbig, 2009). To illustrate, when talking about the status of marriages, one can focus on (1) the percentage of marriages that last ten years or longer or (2) the percentage of marriages that are divorced within the first ten years. Research on the negativity bias in truth judgments generally observed that individuals use the framing of the statement itself as a cue to gauge truthfulness (Hilbig, 2009, 2012b, 2012a). Ceteris paribus, individuals perceive the negatively framed information (2) more likely true than the positively framed information (1).

\section{The negativity bias in truth judgments}

The negativity bias in truth judgments (Hilbig, 2009) is consistent with the broadly observable principle that negative instances tend to be more influential than comparably positive ones (Baumeister, Bratslavsky, Finkenauer, \& Vohs, 2001). This general bad-is-stronger-than-good principle applies to everyday events, major life events (e.g., trauma), close relationship outcomes, social network patterns, interpersonal interactions, and learning processes. Presumably this general principle arises due to the potentially detrimental impact of negative (compared to positive) information and events on the organisms' survival. Moreover, the self seems to be more motivated to avoid bad self-definitions than to pursue good ones, and therefore bad information is considered to be more salient and diagnostic, and is processed more thoroughly compared to good information (Baumeister et al., 2001).

The general negativity bias also pertains more specifically to judgments of truth: messages that are formally equivalent are deemed more true when framed negatively compared to positively (Hilbig, 2009). Different accounts can be recruited to explain this bias. For instance, negative instances attract more attention (Pratto \& John, 1991) and are perceived as more informative (Peeters \& Czapinski, 1990), as negative instances are more rare and more threatening (Dijksterhuis \& Aarts, 2003; Lewicka, Czapinski, \& Peeters, 1992; Peeters \& Czapinski, 1990). Due to higher diagnosticity and salience, negative (bad) information is processed more thoroughly than positive (good) information (Baumeister et al., 2001). More thorough, deeper, or repeated processing can then increase the messages' persuasiveness (Petty \& Brinol, 2008; Shiv, Britton, \& Payne, 2004).

In regards to judgments of truth, Hilbig (2012a) argues that a negative frame might not only lead to more thorough processing, but instead to a stimulation of more attention or activation, which, in turn, allows for easier retrieval of relevant knowledge or generation of evidence. More specifically, the negative frame results in a more fluent retrieval or generation of relevant information, which suggests more fluent processing, and an associated higher subjective veracity 
(Hilbig, 2012a, p. 39). As described by Schwarz and Jalbert (this volume), the processing experience of fluency can be used as an alternative basis to evaluate the truthfulness of information. More specifically, when evaluating plausibility or coherence, individuals may rely on fluency to answer questions such as "Is it compatible with other things I believe?" or "Is it internally consistent?" (see Schwarz \& Jalbert, this volume).

\section{Refining the perspective on the negativity bias}

Previous research (Hilbig, 2012b) described the negativity bias as a general response bias. Using a multinomial processing tree model, Hilbig (2012b) found support that a bias in responses, and not differences in knowledge, accounts for the framing effect. Given insufficient knowledge, individuals are more likely to guess "true" when faced with a negatively framed compared to positively framed (identical) statistical statement.

This chapter offers an extended perspective on the negativity bias in judgments of truth. In our own work, we have investigated potential moderating circumstances of the occurrence of a negativity bias in judgments of truth. In a first study, we developed eight correct statements about women in German-speaking countries. The statements related to topics of health, well-being, and social security. Participants read either a negatively framed or positively framed version of the statements and subsequently judged each statements' truthfulness. To our surprise, and inconsistent with prior evidence reported by Hilbig (2009), a first analysis yielded a positivity bias; that is, statements framed positively were more likely to be judged as true compared to negatively framed statements (Jaffé \& Greifeneder, 2019). Against the background of this evidence, it appears that there is more to understand about the negativity bias than previously thought. This chapter summarizes findings on three groups of potential moderating variables: individuals' expectations, the source of negativity, and psychological distance toward the statements' content. Furthermore, this chapter discusses other potentially influencing variables on individuals' biases in judgments of truth.

\section{Potential moderators of the negativity bias in judgments of truth}

\section{Expectations}

The preceding review has highlighted that individuals use different strategies to evaluate a statements' truthfulness, for example, its plausibility (Dunwoody, 2009; Reder, 1982). Previous negativity bias research indicates that negative information might appear more plausible (see, e.g., Hilbig, 2009). However, although valence of the frame is the key variable in negativity bias research, it is not the only possible cue that individuals may rely on when gauging plausibility and truthfulness. Furthermore, interactions between framing and other cues are 
conceivable. For instance, Koch and Peter (2017) investigate the occurrence of a negativity bias in the context of political communication and argue that negativity is associated with news, and positivity with persuasion attempts. In particular, individuals might have learned that politicians sharing negative information are sharing news, which increases perceptions of truthfulness. In contrast, a politician sharing positive information may raise suspicion that he or she just wants to persuade the recipient, therefore triggering reactance and doubt, resulting in decreased perceptions of the message's truthfulness. These findings suggest that other communication cues - here communication context - may interact with frame, and thus may moderate negativity bias findings. In the case made by Koch and Peter (2017), the context should strengthen the generally observed negativity bias, as the negative compared to positive framing is even more likely to be perceived as true.

Koch and Peter (2017) suggest that context channels expectations about what is more plausible. In extending this general notion of expectations, we argue that it matters whether the message itself meets or clashes with an individual's expectations. To illustrate, learning that $80 \%$ versus $40 \%$ of marriages last at least ten years is a very different piece of information, although the framing of the sentence is identical. The percentage numbers that are presented in the statements may directly influence the plausibility and credibility of a statement. Individuals might ask themselves if the number is coherent with their experiences or knowledge, that is, if the number is in a range in which they would expect it to be. Implausible information may seem fishy and therefore lead to assumptions of deception (Bond et al., 1992). On a more fine-grained level, research on the Expectancy Violation Theory (Burgoon \& Jones, 1976) further suggests that the direction of expectancy violation may be crucial: a positive violation (information is better than expected) leads to a less negative judgment compared to a negative violation (information is worse than expected).

Jaffé and Greifeneder (2019) systematically tested the effect of individuals' expectations in regard to the percentage numbers and found throughout four studies that individuals' expectations moderate the negativity bias. Using a new set of items, the initial studies in this line failed to replicate the negativity bias. As an example, an original and negatively framed statement read " $61 \%$ of German-speaking women are dissatisfied with their looks" whereas the positively framed version read " $39 \%$ of German-speaking women are satisfied with their looks". Participants were more likely to judge the positively framed version as true compared to the negatively framed version. The authors then exploratorily investigated individuals' expectations in regards to the stated content. Participants' mean expectations differed markedly from the true values presented in the initial study. In regards to the exemplary statement, participants believed that only $54 \%$ of women would be dissatisfied with their looks (negative frame) and 45\% were satisfied with their looks (positive frame). More importantly, when looking at all eight statements, a systematic pattern emerged as a function of over-/underestimation and truth judgments when comparing 
data across studies: a negativity bias in judgments of truth was more likely to occur when the likelihood of an aspect was overestimated in the negatively framed version and underestimated in the positively framed version. Building on this insight, we systematically adjusted the numbers in negatively framed statements to be lower than expected in a subsequent study. The new statements then read, for example, " $41 \%$ of German-speaking women are dissatisfied with their looks" (negatively framed) or "59\% of German-speaking women are satisfied with their looks" (positively framed). With this change in place, a negativity bias could be created for the same set of items where a positivity bias was observed in the initial study. In a next step, we systematically decreased and increased numbers in both framing conditions, showing statements framed negatively and positively with numbers higher or lower than expected. This setup allowed to investigate the impact of under- versus overestimating in the context of framing. While expectations had no consistent effects for positive frames, overestimation (compared to underestimation) led to a higher likelihood of perceived truth in the negative framing condition.

These results indicate that expectations with regard to the stated content play a crucial role in the occurrence of the negativity bias. Using the same set of statements, a negativity and a positivity bias could be found, depending on how the numbers presented deviated from individuals' expectations. Presumably this is because learning that actual numbers are lower than expected for something negative is good news, and therefore individuals have a tendency to believe it to be true. In turn, learning that the actual numbers are higher than expected for something negative is bad news, which may trigger a preference for this statement to be false. This tendency matches the general definition of a self-serving bias as a "cognitive or perceptual process that is distorted by the need to maintain and enhance self-esteem" (Forsyth, 2008, p. 429). Although such optimistic perspectives on the outside world reflect a bias, believing in good news and discarding bad news might be a helpful tendency, as optimistic tendencies might promote better health and well-being (Taylor \& Brown, 1988).

\section{Implications of the impact of expectations}

If expectations impact the outcome of judgments of truth, those interested in disseminating fake news and post-truth politics may take advantage. In the worst case, a false statement is communicated in a way that mocks credibility by systematically underbidding individuals' expectations in regards to negative concerns. As a result, individuals may be well advised to pay special attention to the statement's details and how they relate to their own expectations. Am I surprised that the numbers are so high or low? Have the numbers eventually been chosen to exceed or fall below expectations? How does reading such a statement make me feel? Questions like these might be asked to activate a mindful handling of ambivalent information: somebody might try to make the statement feel good and therefore true. 


\section{Sources of negativity}

It is noteworthy that the negativity bias has been investigated with framing statements either negatively or positively. What does framing negatively or framing positively exactly mean? The working definition is to describe something in positive versus negative ways, without changing content. To illustrate, one of Hilbig's original statements (2012b) reads: "In Africa, 40\% of people make less than 1 Dollar per day" (negatively framed) and "In Africa, 60\% of people make more than 1 Dollar per day" (p. 46). However, another exemplary statement reads: " $20 \%$ of German under-17-year-olds are smokers" (negatively framed) and " $80 \%$ of German under-17-year-olds are non-smokers" (positively framed, emphasis added). This illustrates that there are different ways to build a negative versus positive frame: on the one hand, one can focus on concept valence and present a negative (earning only very little money) versus positive concept (earning a little more money). On the other hand, one can focus on semantic negation. By negating a positive concept a negative frame can be derived, and by negating a negative concept, a positive frame can be built (see Jaffé \& Greifeneder, 2019).

Previous research that is cited in the context of the negativity bias in judgments of truth is often related to the concept valence of information (e.g., Baumeister et al., 2001). Negation, however, is not discussed as often, but, as we described earlier, also allows to build a negative or positive frame. Furthermore, the arguments why negative information could have a stronger impact might also pertain to negation, as research indicates that actively encoding negated statements demands controlled processing (Deutsch, Kordts-Freudinger, Gawronski, \& Strack, 2009). Just as when focusing on the negative frame, negation could also lead to more thorough processing that could, in turn, increase perceptions of plausibility.

To allow for a better understanding of framing effects, it is critical to disentangle the potential drivers of the framing: concept valence of a statement (negative versus positive) and whether the statement is semantically negated or not. That is, both forms of negativity need to be separately manipulated in order to understand what drives the effect of the negativity bias. To this end, Jaffé and Greifeneder (2020a) conducted a set of studies in which they systematically varied valence and negation (see Table 7.1 for an exemplary item).

TABLE 7.1 Exemplary item with an orthogonal variation of concept valence and negation

\begin{tabular}{|c|c|c|c|}
\hline & & \multicolumn{2}{|l|}{ Concept valence } \\
\hline & & Positive & Negative \\
\hline \multirow[t]{2}{*}{ Negation } & Present & $\begin{array}{l}30 \% \text { of adults in Germany } \\
\text { are not free from allergies. }\end{array}$ & $\begin{array}{c}70 \% \text { of adults in Germany do } \\
\text { not suffer from allergies. }\end{array}$ \\
\hline & Absent & $\begin{array}{c}70 \% \text { of adults in Germany } \\
\text { are free from allergies. }\end{array}$ & $\begin{array}{l}30 \% \text { of adults in Germany } \\
\text { suffer from allergies. }\end{array}$ \\
\hline
\end{tabular}


The authors find that negation contributes to the negativity bias, meaning that negated statements are generally more likely to be judged as true. Why does negation play such an important role? One might speculate that the integration of a negation into a sentence could also signal expertise and preciseness of the communicator. If a negation is used, the communicator must possess a certain level of knowledge about the topic - how else could they be so specific in their phrasing?

In addition to the increase in specificity, a negation could also increase the realm of possible states. Looking back at the example provided in Table 7.1, there might be many ways in which something is not the case ("not suffering from allergies", e.g., by not having an allergy at all, by not noticing one's allergy, or by not actually suffering from it), but usually only one way in which something is the case ("suffering from allergies", i.e., having and suffering from an allergy). If there are indeed more ways how something is not the case than how something is the case, relying on these base rate differences when judging truth might be a very reasonable thing to do, especially when not having any specific knowledge. Furthermore, if participants have no previous knowledge and simply judge the plausibility by trying to imagine potential scenarios, it might be easier to imagine scenarios that pertain to the negated version but more difficult to imagine scenarios for the not-negated version, as it allows for less variety.

Other work in this volume also refers to the impact of negation (see chapter by Marsh \& Stanley, this volume). The authors describe recent findings that individuals are better at correcting false beliefs when they initially believed in a negated claim, and then received a not-negated claim (compared to first learning a not-negated piece of information, which should then be corrected by learning a negated claim). One could speculate that individuals are cognitively more likely to replace a negated claim with a simpler and more specific positive claim than the other way around.

\section{Implications of the impact of negation}

So far, the data from Jaffé and Greifeneder (2020a) indicate that negation is another important piece of the puzzle on how individuals proceed when forming judgments of truth. Again, negation could be used in a manipulative manner when communicating fake news and post-truth information. A false statement could contain a negation to appear more credible and to systematically lead individuals to judge the information as true. In a protective fashion, again, individuals could carefully investigate whether the negation to them appears plausible. Why is a certain piece of information presented in a negated way? What if individuals simply reframe the item without the negation? Does it sound different?

\section{Psychological distance}

A third likely candidate for moderating the occurrence of a negativity bias in judgments of truth is the mindset of individuals, as it influences how individuals 
integrate and weigh veracity cues. Here we focus on individuals' construal level (Liberman \& Trope, 2008; Trope \& Liberman, 2003, 2010), as one theory on mindsets that has been related to how individuals encode, process, and integrate information. Construal Level Theory (CLT; Liberman \& Trope, 2008) assumes that individuals can think about objects or events on a continuum from concreteness to abstractness. When thinking about a forest in detail, individuals might picture the colors of stems, of branches, of different leaves and therefore have a very concrete representation of the concept forest. The other extreme would be thinking of a forest in absolute abstract patterns, such as a green recreational location in the countryside. One can easily see that depending on where on this continuum individuals construe, very different pieces of information about a forest are considered. On a concrete mindset level (or also low construal level), individuals include a high number of specific details, but also subordinate information. On a more abstract mindset level (or high construal level) instead, individuals include less details but more abstract and central components of the object or event, considered as superordinate information. Construal Level Theory assumes that individuals construe on a lower level if objects and events are psychologically close (in time, space, socially, or in probability of occurrence), whereas individuals construe on a higher level if objects and events are psychologically distant.

Construal Level Theory makes specific assumptions about the weighing of positive and negative information (Trope \& Liberman, 2010). The authors assume that arguments in favor are superordinate to arguments against something, as the subjective importance of cons depends on whether or not pros are present more than the reverse (Eyal, Liberman, Trope, \& Walther, 2004; Herzog, Hansen, \& Wänke, 2007). Common examples are medical treatments. To illustrate: if a medical treatment seems beneficial (has pros), only then would one consider and discuss the potential negative side effects (cons). If, however, no benefits are apparent (no pros), potential side effects seem irrelevant and will not be discussed. Equating pros with positive information and cons with negative information, Construal Level Theory allows for the prediction that when individuals construe on a higher level, positive compared to negative information is processed more thoroughly and therefore is deemed more true. This notion receives support from several angles. For instance, it has been shown that the mental salience of positive and societal outcomes of an action increases as social distance increases, and the framing of persuasive messages in terms of gains compared to losses becomes more powerful when participants make judgments for socially distant versus proximal entities (Nan, 2007). Individuals also seem to judge both negative and positive emotional experiences as more pleasant when construing abstractly, as abstractness increases the positivity of these experiences (Williams, Stein, \& Galguera, 2014). Presumably, while individuals are concerned with negative and preventional outcomes in the here-and-now (such as disappointing oneself when failing an exam), with increasing psychological distance (two weeks before the exam) individuals also focus on positive and promotional 
outcomes (such as getting a high score; Pennington \& Roese, 2003). Summing up, positive aspects are more strongly weighed in conditions of abstractness or psychological distance, whereas more negative concerns come into play when construing more concretely and decreasing distance.

Against this background, we (Jaffé \& Greifeneder, 2020b) hypothesized that the negativity bias in judgments of truth is particularly pronounced in conditions of psychological proximity and when individuals construe concretely, but not as strong in conditions of psychological distance and when individuals construe abstractly. We investigated this hypothesis in a first set of studies, using negatively and positively framed statements pertaining to places spatially close to the participants versus far away, therefore manipulating psychological distance via spatial distance. The results of these first studies provide preliminary support for the attenuation or reversal of the negativity bias with increased psychological distance. However, this first set of studies awaits further testing and replication, as for example other distance dimensions may be investigated. Furthermore, it appears interesting to investigate idiosyncratic differences in psychological distance. Depending on the content of the statement, perceptions of relevance and importance might be changed, and a highly relevant topic might per se feel psychologically closer than another one that individuals do not care about.

\section{Implications of the impact of psychological distance}

Individuals might benefit from learning that psychological distance impacts the weighing of information. To free themselves from this impact, individuals could attempt to vary the distance toward the statement by themselves. How would they feel about the statement if it was related to a faraway place instead of their hometown? Or if it concerned sometime in the past and not now? Applying this procedure could aid individuals to overcome their own negativity bias in judgments of truth, as by increasing psychological distance, negative instances may be weighted less strongly and might be less likely to increase perceived plausibility and credibility.

\section{The mechanisms underlying negativity bias in judgments of truth}

The current overview indicates that there is more to tell about the negativity bias in judgments of truth. The original research (Hilbig, 2009, 2012b) has shown that negatively framed versus positively framed statements are more likely to be judged as true. This chapter argues that a negative frame alone might not always be a sufficient condition for an increase in plausibility and expected truthfulness. Other aspects such as individuals' expectations, the semantics of the statements, and individuals' mindset at least moderate the impact of the valence of the frame on judgments of truth. 
Investigating potential moderators of the negativity bias appears commendable, as it allows a deeper understanding of the underlying processes. Several explanations for the general negative-is-stronger-than-good have been discussed in the literature, such as that negative instances are perceived as more informative (Peeters \& Czapinski, 1990), that negative instances stand a higher chance of being cognitively elaborated (Lewicka, 1997; Peeters \& Czapinski, 1990), and that negative instances are detected more reliably, because they are more rare and more threatening (Dijksterhuis \& Aarts, 2003). Other research also taps into this notion, showing that positive information is more alike than negative information (Alves, Koch, \& Unkelbach, 2017; Koch, Alves, Krueger, \& Unkelbach, 2016). Positive information is therefore more redundant, whereas negative information is more distinct, and individuals therefore benefit from taking it into account (Alves et al., 2017). Last but not least, negative framing and truth might be perceived to be associated, because other individuals are less likely to lie to us when bringing bad news (Hilbig, 2009; see also Koch \& Peter, 2017 for a perspective on politicians' communication). All of these suggested underlying processes are defined by a strong cognitive perspective. This is consistent with previous research that individuals with good numeracy skills are less susceptible to framing effects (Peters, 2012), which might indicate that cognitive capacity is especially relevant when investigating biases in truth judgments. However, the research by Jaffé and Greifeneder (2019) about expectations suggests that motivational mechanisms may be important, too, and have been neglected so far in the array of possible of underlying processes. To recapitulate, the authors observed that negative facts that are less frequent (and therefore eventually also less negative) than expected are more likely judged true. Perhaps this is because individuals misattribute the relief of a better-than-expected world to truth or that they simply wish that good things are true.

\section{Future directions}

Given that the mere phrasing of information, be it valence, negation, or distance, impacts individuals' judgments of truth, implications of research on the negativity bias are likely far reaching and important for all types of communication, be it spoken or written. Implications pertain, for instance, to detecting deception in interpersonal interactions (Bond et al., 1992), judging the truthfulness of messages sent by politicians (Koch \& Peter, 2017), or survey responding in dayto-day polls or longitudinal representative surveys. Further research may fruitfully investigate how framing information impacts individuals' judgments across a multitude of different contexts. In our work, we often focus on domains in which we believe there is a shared consensus about what is positive (e.g., health) and what is negative (e.g., illness). However, looking at a variety of contexts could allow for investigations on how idiosyncratic beliefs and opinions might interact with framing effects in judgments of truth. Furthermore, research could also investigate how effects might not only change depending on the context, 
but also how effects might change when statements increase or decrease in relevance. As an example, when comparing a statement that informs individuals about a personal risk (versus a risk that impacts their opponents), attributes of the statement might be processed differently.

Furthermore, future research may also investigate potential differences between information shared offline versus through online channels. Looking at the incredible speed of information sharing that is characteristic for communication over the internet in general, or social media platforms more specifically, it is important to understand differential processing of information (see Baumeister et al., 2001) and its impact on subsequent judgments of truth. One could speculate that individuals are more inclined to deeply process a newspaper article that they read after breakfast on a Sunday morning, compared to a news snippet in their Facebook online feed. This difference could then moderate potential framing biases. If, for example, negation is indeed an indicator for the expertise of the communicator, as we speculated, it may have a more powerful impact in conditions of low processing intensity, such as the Facebook online feed (cf. the Elaboration Likelihood Model of Persuasion, Petty \& Cacioppo, 1986).

Technological progress has made it easier to spread information, but it has also become easier to fact check information. However, given the sheer amount of shared information, the likelihood of engaging in fact checking might be lower. This opens the door widely for effects of framing, negation, or expectations as documented here.

We have argued throughout this chapter that further knowledge about the negativity bias may help those who wish to disseminate fake news, and those who wish to protect themselves or others against unwanted manipulation. In a battle for truth (or falsehood), knowledge about the power of phrasing is likely important for all players.

\section{Conclusion: new perspectives on the negativity bias in judgments of truth}

In this chapter, we discussed the negativity bias in judgments of truth. We highlighted why, in post-truth times, it is important to better understand how individuals come to make their judgments of truth. Deep-diving into the concept of the negativity bias, we offered insights into potential moderators of the negativity bias that impact individuals' tendency to believe a certain statement to be true. We conclude that, especially for those who intend to debias, it is important to gain insight ino the malleability of truth judgments and to understand how slight adjustments in the framing or content of information impact evaluations.

\section{References}

Alves, H., Koch, A., \& Unkelbach, C. (2017). Why good is more alike than bad: Processing implications. Trends in Cognitive Sciences, 21, 69-79. https://doi.org/10.1016/j. tics.2016.12.006 
Anolli, L., Balconi, M., \& Ciceri, R. (2003). Linguistic styles in deceptive communication: Dubitative ambiguity and elliptic eluding in packaged lies. Social Behavior and Personality: An International Journal, 31, 687-710. https://doi.org/10.2224/sbp. 2003.31.7.687

Baumeister, R. F., Bratslavsky, E., Finkenauer, C., \& Vohs, K. D. (2001). Bad is stronger than good. Review of General Psychology, 5, 323-370. https://doi.org/10.1037// 1089-2680.5.4.323

Bond, C. F., Jr., Omar, A., Pitre, U., Lashley, B. R., Skaggs, L. M., \& Kirk, C. T. (1992). Fishy-looking liars: Deception judgment from expectancy violation. Journal of Personality and Social Psychology, 63, 969-977. http://dx.doi.org/10.1037//0022-3514. 63.6.969

Buller, D. B., Burgoon, J. K., White, C. H., \& Ebescu, A. S. (1994). Interpersonal deception VII behavioral profiles of falsification, equivocation, and concealment. Journal of Language and Social Psychology, 13, 366-395. https://doi.org/10.1177/0261927X94134002

Burgoon, J. K., Blair, J. P., \& Strom, R. E. (2008). Cognitive biases and nonverbal cue availability in detecting deception. Human Communication Research, 34, 572-599. https://doi.org/10.1111/j.1468-2958.2008.00333.x

Burgoon, J. K., \& Jones, S. B. (1976). Toward a theory of personal space expectations and their violations. Human Communication Research, 2, 131-146. https://doi. org/10.1111/j.1468-2958.1976.tb00706.x

Dechêne, A., Stahl, C., Hansen, J., \& Wanke, M. (2010). The truth about the truth: A meta-analytic review of the truth effect. Personality and Social Psychology Review, 14, 238-257. https://doi.org/10.1177/1088868309352251

Deutsch, R., Kordts-Freudinger, R., Gawronski, B., \& Strack, F. (2009). Fast and fragile: A new look at the automaticity of negation processing. Experimental Psychology, 56, 434-446. https://doi.org/10.1027/1618-3169.56.6.434

Dijksterhuis, A., \& Aarts, H. (2003). On wildebeests and humans: The preferential detection of negative stimuli. Psychological Science, 14, 14-18. https://doi.org/10.1111/14679280.t01-1-01412

Dunwoody, P. T. (2009). Theories of truth as assessment criteria in judgment and decision making. Judgement and Decision Making, 4, 116-125.

Eyal, T., Liberman, N., Trope, Y., \& Walther, E. (2004). The pros and cons of temporally near and distant action. Journal of Personality and Social Psychology, 86, 781-795. https:// doi.org/10.1037/0022-3514.86.6.781

Forsyth, D. R. (2008). Self-serving bias. In W. A. Darity (Ed.), International encyclopedia of the social sciences (2nd ed., Vol. 7, p. 429). Retrieved from http://scholarship.richmond. edu/jepson-faculty-publications

Grice, H.-P. (1975). Logic and conversation. In P. Cole \& J. L. Morgan (Eds.), Syntax and semantics 3: Speech arts (pp. 41-58). New York: Academic Press.

Hammond, K. R. (1996). Human judgment and social policy. New York: Oxford University Press.

Hammond, K. R. (2007). Beyond rationality. Oxford: Oxford University Press.

Herzog, S. M., Hansen, J., \& Wänke, M. (2007). Temporal distance and ease of retrieval. Journal of Experimental Social Psychology, 43, 483-488. https://doi.org/10.1016/j.jesp. 2006.05.008

Hilbig, B. E. (2009). Sad, thus true: Negativity bias in judgments of truth. Journal of Experimental Social Psychology, 45, 983-986. https://doi.org/10.1016/j.jesp.2009.04.012

Hilbig, B. E. (2012a). Good things don't come easy (to mind): Explaining framing effects in judgments of truth. Experimental Psychology, 59, 38-46. https://doi.org/ 10.1027/1618-3169/a000124 
Hilbig, B. E. (2012b). How framing statistical statements affects subjective veracity: Validation and application of a multinomial model for judgments of truth. Cognition, 125, 37-48. https://doi.org/10.1016/j.cognition.2012.06.009

Jackson, J. (2017). Fact-checkers are weapons in the post-truth wars, but they're not all on one side. The Guardian. Retrieved from www.theguardian.com/media/2017/feb/15/ fact-checkers-are-weapons-in-the-post-truth-wars-but-theyre-not-all-on-one-side

Jaffé, M. E., \& Greifeneder, R. (2019). Less than I expected and oh so true? On the interplay between expectations and framing effects in judgments of truth. Journal of Language and Social Psychology, 1-21. https://doi.org/10.1177/0261927X19869392

Jaffé, M. E., \& Greifeneder, R. (2020a). Negative or negated, thus true? An investigation of concept valence and semantic negation as drivers of framing effects in judgments of truth. Manuscript in Preparation.

Jaffé, M. E., \& Greifeneder, R. (2020b). Negative is true here and now, but not so much there and then: On the impact of psychological distance on the negativity bias. Manuscript in Preparation.

Koch, A., Alves, H., Krueger, T., \& Unkelbach, C. (2016). A general valence asymmetry in similarity: Good is more alike than bad. Journal of Experimental Psychology: Learning, Memory, and Cognition, 42, 1171-1192. https://doi.org/10.1037/xlm0000243

Koch, T., \& Peter, C. (2017). Effects of equivalence framing on the perceived truth of political messages and the trustworthiness of politicians. Public Opinion Quarterly, 81, 847-865. https://doi.org/10.1093/poq/nfx019

Lewicka, M. (1997). Is hate wiser than love? Cognitive and emotional utilities in decision making. In R. Ranyard, W. R. Crozier, \& O. Svenson (Eds.), Decision making: Cognitive models and explanations. London, UK: Routledge.

Lewicka, M., Czapinski, J., \& Peeters, G. (1992). Positive-negative asymmetry or "when the heart needs a reason". European Journal of Social Psychology, 22, 425-434. https:// doi.org/10.1002/ejsp.2420220502

Liberman, N., \& Trope, Y. (2008). The psychology of transcending the here and now. Science, 322, 1201-1205. https://doi.org/10.1126/science.1161958

Marsh, E. J., \& Stanley, M. L. (n.d.). False beliefs: Byproducts of an adaptive knowledge base? In R. Greifeneder, M. E. Jaffé, E. J. Newman, \& N. Schwarz (Eds.), The psychology of fake news: Accepting, sharing, and correcting misinformation (pp. 131-146). Abingdon, UK: Routledge.

Nan, X. (2007). Social distance, framing, and judgment: A construal level perspective. Human Communication Research, 33, 489-514. https://doi.org/10.1111/j.1468-2958. 2007.00309.x

Norman, M. (2016, November 8). Whoever wins the US presidential election, we've entered a post-truth world: There's no going back now. The Independent. Retrieved from www. independent.co.uk/voices/us-election-2016-donald-trump-hillary-clinton-whowins-post-truth-world-no-going-back-a7404826.html

Oxford Dictionary. (2016). Oxford Dictionary Word of the Year 2016.

Peeters, G., \& Czapinski, J. (1990). Positive-negative asymmetry in evaluations: The distinction between affective and informational negativity effects. European Review of Social Psychology, 1, 33-60. https://doi.org/10.1080/14792779108401856

Pennington, G. L., \& Roese, N. J. (2003). Regulatory focus and temporal distance. Journal of Experimental Social Psychology, 39, 563-576. https://doi.org/10.1016/S00221031(03)00058-1

Peters, E. (2012). Beyond comprehension: The role of numeracy in judgments and decisions. Current Directions in Psychological Science, 21, 31-35. https://doi.org/10.1177/096372 1411429960 
Petty, R. E., \& Brinol, P. (2008). Persuasion: From single to multiple to metacognitive processes. Perspectives on Psychological Science, 3, 137-147.

Petty, R. E., \& Cacioppo, J. T. (1986). The elaboration likelihood model of persuasion. In L. Berkowitz (Ed.), Advances in exprimental social psychology (Vol. 19, pp. 123-205). https://doi.org/10.1016/S0065-2601(08)60214-2

Pratto, F., \& John, O. P. (1991). Automatic vigilance: The attention-grabbing power of negative social information. Journal of Personality and Social Psychology, 61, 380-391. https://doi.org/10.1037/0022-3514.61.3.380

Reber, R., \& Greifeneder, R. (2017). Processing fluency in education: How metacognitive feelings shape learning, belief formation, and affect. Educational Psychologist, 52, 84-103. https://doi.org/10.1080/00461520.2016.1258173

Reber, R., \& Schwarz, N. (1999). Effects of perceptual fluency on judgments of truth. Consciousness and Cognition, 8, 338-342. https://doi.org/ccog.1999.0386

Reder, L. M. (1982). Plausibility judgments versus fact retrieval: Alternative strategies for sentence verification. Psychological Review, 89, 250-280. https://doi.org/ 10.1037//0033-295X.89.3.250

Reinhard, M.-A., Greifeneder, R., \& Scharmach, M. (2013). Unconscious processes improve lie detection. Journal of Personality and Social Psychology, 105, 721-739. https:// doi.org/10.1037/a0034352

Schwarz, N., \& Jalbert, M. (n.d.). When news feels true: Intuitions of truth and the acceptance and correction of misinformation. In R. Greifeneder, M. E. Jaffé, E. J. Newman, \& N. Schwarz (Eds.), The psychology of fake news: Accepting, sharing, and correcting misinformation (pp. 73-89). Abingdon, UK: Routledge.

Shiv, B., Britton, J. A. E., \& Payne, J. W. (2004). Does elaboration increase or decrease the effectiveness of negatively versus positively framed messages? Journal of Consumer Research, 31, 199-208. https://doi.org/10.1086/383435

Stanley, M. L., Yang, B. W., \& Marsh, E. J. (2019). When the unlikely becomes likely: Qualifying language does not influence later truth judgments. Journal of Applied Research in Memory and Cognition, 8, 118-129. https://doi.org/10.1016/j.jarmac.2018.08.004

Taylor, S. E., \& Brown, J. D. (1988). Illusion and well-being: A social psychological perspective on mental health. Psychological Bulletin, 103, 193-210. https://doi.org/ 10.1037/0033-2909.103.2.193

Trope, Y., \& Liberman, N. (2003). Temporal construal. Psychological Review, 110, 403421. https://doi.org/10.1037/0033-295X.110.3.403

Trope, Y., \& Liberman, N. (2010). Construal-level theory of psychological distance. Psychological Review, 117, 440-463. https://doi.org/10.1037/a0018963

Unkelbach, C., \& Koch, A. (2019). Gullible but functional? Information repetitions and the formation of beliefs. In J. P. Forgas \& R. F. Baumeister (Eds.), The social psychology of gullibility: Conspiracy theories, fake news and irrational beliefs (pp. 42-60). Abingdonon-Thames: Routledge.

Unkelbach, C., \& Rom, S. C. (2017). A referential theory of the repetition-induced truth effect. Cognition, 160, 110-126. https://doi.org/10.1016/j.cognition.2016.12.016

Vrij, A., \& Mann, S. (2001). Who killed my relative? Police officers' ability to detect real-life high-stake lies. Psychology, Crime \& Law, 7, 119-132. https://doi.org/10.1080/ 10683160108401791

Williams, L. E., Stein, R., \& Galguera, L. (2014). The distinct affective consequences of psychological distance and construal level. Journal of Consumer Research, 40, 11231138. https://doi.org/10.1086/674212 